$\begin{array}{lll}\text { Firas Bahdi, MD } & \text { Shilpa Jain, MD } & \text { Suneal Kumar Agarwal, MD, FACG } \\ \begin{array}{ll}\text { Department of Medicine, } \\ \text { Baylor College of Medicine, } \\ \text { Houston, TX }\end{array} & \begin{array}{l}\text { Assistant Professor, Department } \\ \text { of Pathology and Immunology, } \\ \text { Baylor College of Medicine, } \\ \text { Houston, TX }\end{array} & \begin{array}{l}\text { Assistant Professor, Department of Medicine, } \\ \text { Section of Gastroenterology and Hepatology, } \\ \text { Baylor College of Medicine, } \\ \text { Houston, TX }\end{array} \\ & & \text { H. }\end{array}$

\title{
Cryptosporidiosis in an immunosuppressed patient with persistent diarrhea
}

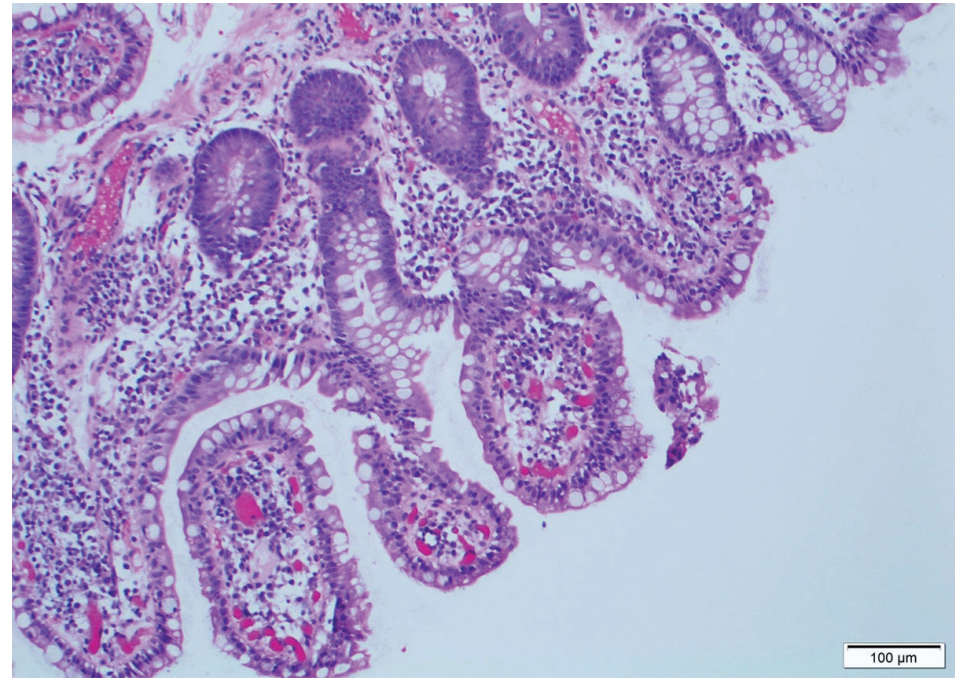

Figure 1. Hematoxylin and eosin stain of terminal ileum biopsy (scale bar $100 \mu \mathrm{m}$ ) revealed marked increased lymphoplasmacytic infiltrate in the lamina propria, with villous blunting.

\footnotetext{
29-Year-Old woman receiving immunoA suppressants for bilateral lung transplant performed 14 years earlier because of a surfactant protein $\mathrm{C}$ deficiency presented with a 1 -month history of worsening watery diarrhea, nausea, vomiting, abdominal cramping, and subjective fevers. She said she had no hematochezia, hematemesis, suspicious food intake, recent contact with sick people, or family history of inflammatory bowel disease.

Her medications included tacrolimus, mycophenolate, and low-dose prednisone with no recent dosage adjustments. Her most recent

tacrolimus level, measured 3 months earlier, was $8.8 \mathrm{ng} / \mathrm{mL}$ (reference range 10-20 ng/ $\mathrm{mL}$ ), and her average absolute lymphocyte count was $4.78 \times 10^{9} / \mathrm{L}$ (reference range 1.18 $\left.3.74 \times 10^{9} / \mathrm{L}\right)$. The physical examination was unremarkable except for mild generalized abdominal tenderness and signs of dehydration.

\section{INVESTIGATING THE CAUSE}

The patient was admitted for intravenous fluid administration and diarrhea workup. The differential diagnosis included a broad array of typical and opportunistic gastrointestinal infections, especially those with a higher incidence in immunosuppressed hosts, including parasites (eg, Giardia, Cryptosporidium), bacteria (eg, Clostridioides difficile, Campylobacter), and viruses (eg, cytomegalovirus). Noninfectious causes including medication toxicity, immunologic reactions, inflammatory bowel disease, and malignancy also were considered.

Results of the complete blood cell count were normal. Her aminotransferase levels were mildly elevated, with an alanine aminotransferase of $60 \mathrm{U} / \mathrm{L}$ (reference range 6-55 U/L) and aspartate aminotransferase of $41 \mathrm{U} / \mathrm{L}$ (reference range 5-34 U/L); alkaline phosphatase and total bilirubin levels were normal. Her tacrolimus level was $16.2 \mathrm{ng} / \mathrm{mL}$. A quantitative cytomegalovirus DNA test was negative.

Stool tests for fecal leukocytes, ova and parasites, $\mathrm{C}$ difficile toxin (using a polymerase chain reaction test), Shiga toxins, Giardia antigen, and pancreatic fecal elastase were normal. The fecal calprotectin level was $189 \mu \mathrm{g} / \mathrm{g}$ (reference range $0-120 \mu \mathrm{g} / \mathrm{g}$ ). 


\section{BAHDI AND COLLEAGUES}

\section{Further workup}

Abdominal computed tomography with contrast enhancement showed no acute intraabdominal abnormalities.

The patient underwent upper endoscopy and colonoscopy, with normal findings. Multiple biopsies were taken, including some of the terminal ileum. Results showed nonspecific villous blunting (Figure 1) and many mucosal apical basophilic circular-shaped organisms with epicellular invasion and marked increased lymphoplasmacytic infiltrate in the lamina propria (Figure 2). All of these are consistent with cryptosporidiosis.

Stool sample immunofluorescent assays for Cryptosporidium oocyst antigens later confirmed the diagnosis of cryptosporidiosis.

\section{CRYPTOSPORIDIOSIS}

Cryptosporidium parvum and Cryptosporidium hominis are unicellular parasites that usually cause self-limited diarrhea in immunocompetent hosts; however, they can cause lifethreatening diarrhea in immunocompromised patients, especially those with impaired cellmediated immunity or interferon-gamma production. ${ }^{1}$

The pathophysiology of diarrhea remains unclear. Theories suggest a combination of malabsorption and secretory diarrhea secondary to mucosal attachment, villous architecture distortion, epicellular invasion, inflammatory response, and cellular apoptosis. ${ }^{1-2}$ Cryptosporidia can also involve the biliary system by spreading through the intestinal lumen.

Direct immunofluorescence and polymerase chain reaction testing are the most sensitive and specific diagnostic tests for cryptosporidiosis. ${ }^{3}$ Although routine stool examination for ova and parasites remains the simplest and most widely available test, its sensitivity is limited by low levels of oocyst shedding and variable microscopic expertise.

In general, microscopy of tissue biopsies from the gastrointestinal tract is limited by the patchy distribution of infection; however, it was the key to the diagnosis in our patient.

Therapy in immunocompromised patients, other than those with human immunodefi-
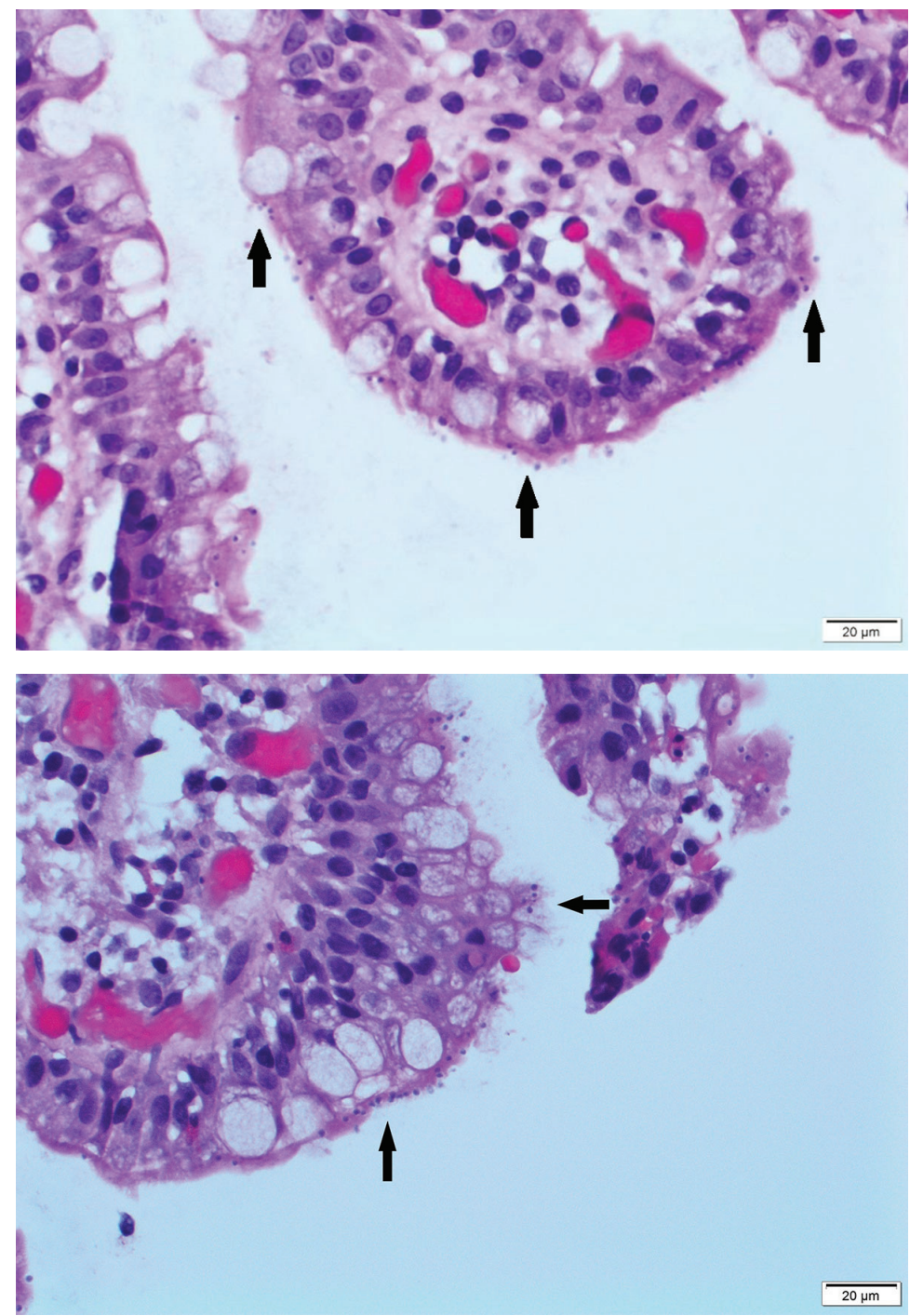

Figure 2. Hematoxylin and eosin stain of terminal ileum biopsy (scale bar $20 \mu \mathrm{m}$ ) revealed many mucosal, apical, basophilic, circular-shaped organisms, with epicellular invasion (black arrows).

ciency virus infection, involves reducing the dose of immunosuppressive therapy and initiating dual antibiotics. ${ }^{4}$

We treated our patient with 14 days of nitazoxanide $500 \mathrm{mg}$ twice daily and azithromycin $500 \mathrm{mg}$ daily and reduced her mycophenolate dose, and her symptoms resolved.

\section{DISCLOSURES}

The authors report no relevant financial relationships which, in the context of their contributions, could be perceived as a potential conflict of interest. 


\section{CRYPTOSPORIDIOSIS}

\section{REFERENCES}

1. Lendner M, Daugschies A. Cryptosporidium infections: molecular advances. Parasitology 2014; 141(11):1511-1532. doi:10.1017/ S0031182014000237

2. Heyworth MF. Parasitic diseases in immunocompromised hosts. Cryptosporidiosis, isosporiasis, and strongyloidiasis. Gastroenterol Clin North Am 1996; 25(3):691-707. doi:10.1016/s0889-8553(05)70269-7

3. Adeyemo FE, Singh G, Reddy P, Stenström TA. Methods for the detection of Cryptosporidium and Giardia: from microscopy to nucleic acid based tools in clinical and environmental regimes. Acta Trop 2018; 184:15-28. doi:10.1016/j.actatropica.2018.01.011

4. Legrand F, Grenouillet F, Larosa F, et al. Diagnosis and treatment of digestive cryptosporidiosis in allogeneic haematopoietic stem cell transplant recipients: a prospective single centre study. Bone Marrow Transplant 2011; 46(6):858-862. doi:10.1038/bmt.2010.200

Address: Suneal Kumar Agarwal, MD, FACG, Department of Medicine, Baylor College of Medicine, 7200 Cambridge Street, Suite 8B, Houston, TX 77030; suneal.agarwal@bcm.edu 